\title{
Outcome of decompressive operative procedure in the treatment of degenerative lumbar spinal canal stenosis: experience of managing consecutive 25 cases
}

\author{
Saha $\mathrm{AC}^{\mathrm{a}}$, Masud MH ${ }^{\mathrm{b}}$, Haque MAc ${ }^{\mathrm{c}}$, Sarker MZH
}

\begin{abstract}
Background: Lumbar spinal canal stenosis (LSCS) is a common medical disorder due to degenerative changes in the middle age and older individual. In this condition, narrowing of lumbar spinal canal and nerve root canal leads to painful, debilitating compression of spinal nerves and blood vessels. Decompressive surgery in lumbar spinal canal stenosis is one of modern methods of treatment.

The objective of this study was to evaluate the outcome of decompressive operative management in degenerative lumbar spinal canal stenosis.

Methods: Thiswas a prospective interventional study carried out at National Institute of Traumatology and Orthopaedic Rehabilitation (NITOR) and City Hospital, Lalmatia, Dhaka from October 2012 to December 2014.Total number of patients were 25 who underwent decompressive surgical procedures. Each of patients was evaluated by the visual analogue scale (VAS) for pain, disability by using Oswestry disability index (ODI) and ModifiedMacnab Criteria (MMC)for assessment of improvement.

Results: This was a prospective interventional study carried out at National Institute Of Traumatology and Orthopaedic Rehabilitation (NITOR) and City hospital, Lalmatia, Dhaka from October 2012 to December 2014. Out of 25 patients, 19 patients (76\%)were male and 6 patients (24\%) were female, age ranged from 38-65 years with the mean age $48.50 \pm 8.65$ years. Sixteen (64\%) patients were manual worker and 9 patients (36\%) were sedentary worker. Sixteen (64\%) patients had multilevel stenosis and 9 patients (36\%) had single level stenosis. The mean follow up duration was 1.5 years (range: 1-3 years). Mean estimated blood loss was 150ml (range : 100-200ml), mean surgery time was 130mutes (range: 80-180min) and average hospital stay was 7 days (range: 4-10 days). Only 1 patient (4\%) had discitis, 1 patient (4\%) had superficial wound infection and 1 patient (4\%) had dural tear. As MMC, 21 (84\%) patients was poor before operation and after operation at 12 months follow up 8 patients (32\%) had excellent, 12 patients (48\%) had good, 4 patients (16\%) had fair and 1 patient (4\%) had poor functional outcome. Mean $(S D)$ ODI were $75.40( \pm 5.01)$ before operation and reduced to $8.36( \pm 13.54)$ after operation at $3^{\text {rd }}$ (12 month) follow up. Mean (SD) VAS was 7.12 ( \pm 0.86) before operation and reduced to 1.46 ( \pm 1.31 ) after operation at $3^{\text {rd }}$ (12 month) follow up. Twenty (80\%) patients had satisfactory functional outcome.
\end{abstract}

Conclusion: Decompressive operation is an effective, safe and acceptable method of treatment in degenerative lumbar spinal canal stenosis (LSCS).

Key words: Decompressive operative procedure, degerative lumbar spinal canal stenosis.

(BIRDEM Med J 2020; 10(2): 103-107)

Author information

a. Apel Chandra Saha, Assistant Professor (Ortho-Surgery), Cumilla Medical College, Cumilla

b. Md. Hasan Masud, Professor of Orthopaedics, NITOR, Dhaka.

c. Md. Abdul Haque, Associate Professor (Ortho-Surgery), Cumilla Medical College, Cumilla

d. Mohammad Zulfiqur Haider Sarker, Medical Officer (Ortho \& Trauma) Department of orthopaedics, Cumilla Medical College \& Hospital

Address of correspondence to: Dr. Apel Chandra Saha, Assistant Professor (Ortho-Surgery), Cumilla Medical College, Cumilla. Email:dr.apel@yahoo.com

Received: October 26, 2019

\section{Introduction}

Lumbar spinal canal stenosis (LSCS) is a common medical disorder in the aging population and is characterized by narrowing of lumbar spinal canal and nerve root canal leading to compression of the neural and vascular structures in the canal. Neurogenic claudication recognized as aching, cramping or heaviness in the buttock, thighs or lower legs with standing is the classical clinical feature associated with LSCSand causes diminished function and impaired quality of life. Symptoms are aggravated by prolonged 
standing, activity or lumbar extension and is relieved by sitting, lying down or lumbar flexion.

Approximately 1.2 million people in the United States have back and leg pain that is related to spinal stenosis. ${ }^{1}$ Degenerative lumbar spinal canal stenosis is secondary to loss of disc height with or without buldging of the intervertebral disc and hypertrophy of facet joints and the ligamentumflavum. Fibrosis is the main cause of ligamentumflavum hypertrophy which is caused by accumulation of mechanical stress, especially along the dorsal aspect of the ligamentum flavum. $^{2}$

Progression of neurological deficit or the development ofcaudaequina syndrome are two indications for urgent operative decompression. Non operative management has been shown to be less successful in patients who have more severe pain and functional limitation. ${ }^{3}$

Many surgical techniques, all based on the principles of decompression alone or decompression and fusion with or without instrumentation have been described. ${ }^{4}$ Decompressive procedure involves removal of disc and removal of the posterior elements including the laminae, spinous process, interspinous ligaments and sometimes undercutting the facet joints. ${ }^{5}$

Spinal canal stenosis is most commonly classified as either primary, caused by congenital abnormality or a disorder of postnatal development or secondary (acquired stenosis) resulting from degenerative changes or as a consequence of local infection, trauma or surgery.

In our study we focus on the most common cause, a slowly progressive degenerative process that predominates at the three lower lumbar levels.

The aim of this study was to evaluate the results of decompressive operative procedure in the treatment of degenerative lumbar spinal canal stenosis.

\section{Methods}

Thiswas a prospective interventional study carried out at National Institute of Traumatology and Orthopaedic Rehabilitation (NITOR) and City Hospital,Lalmatia, Dhaka from October 2012 to December 2014. Total number of patients were 25 who underwent decompressive surgical procedures.
Among them 19 (76\%)patients were males and 6 (24\%) patients were females, age ranged from 38 to 65 years with a follow up period of 1-2 years (average: 18 months). Patients were selected on the basis of history, physical examination, radiological and Magnetic resonance imaging (MRI) findings. It is also selected on the basis of inclusion and exclusion criteria.

\section{Inclusion Criteria}

Patients diagnosed with degenerative lumbar spinal canal stenosis (mid sagital anterior posterior diameter of the lumbar spinal canal at the most constricted level did not exceed $11 \mathrm{~mm}$ in MRI) of age group between 38-65 years and who failed to conservative treatment for at least 3 months were included in this study.

\section{Exclusion Criteria}

Patients with previous lumbar spine surgery (mostly disc surgery) and those withspondylolytic (isthmic) spondylolisthesisand instability were excluded.

All patients were evaluated clinically and radiologically before and after operations. Each of the patients was also evaluated by visual analogue scale (VAS) for pain, disability by using Oswestry disability index (ODI) and Modified Macnab Criteria (MMC) for assessment of improvement. Statistical analysis was performed by using window based software devised with Statistical Packages for Social Sciences (SPSS - 12) (SPSS Inc, Chicago, IL, USA). A $p$ value of $<0.05$ was considered statistically significant.

\section{Results}

Among 25 patients 19 (76\%) were males and 6 (24\%) were females, age ranged from $38-65$ years with mean age 48.508 .65 years. 16 (64\%) patients were manual workers and $9(36 \%)$ were sedentary workers. Sixteen (64\%) patients had multilevel stenosis and $9(36 \%)$ had single level stenosis. Thirteen (52\%) patients had central stonosis, $4(16 \%)$ had lateral stenosis and $8(32 \%)$ had foraminal stenosis. Mean estimated blood loss was 150 $\mathrm{ml}$ (range: $100-200 \mathrm{ml}$ ), mean surgery time was 130 minutes(range : $80-180 \mathrm{~min}$ ) and mean hospital stay was 7 days (range : 4-10 days). Only 1(4\%) patient had discitis, $1(4 \%)$ patient had superficial wound infection and $1(4 \%)$ patient had dural tear.

Operation at 3rd follow up (12 months), 8 (32\%) patients had excellent, 12 (48\%) patients had good, 4 (16\%) 
patients had fair and $1(4 \%)$ patient had poor functional outcome. Mean (SD) ODI was 75.40 ( 5.01) before operation As MMC, most of the patients 21(84\%) was poor before operation. But after and reduced to 18.36 (13.54) after operation at 3rd (12 months) follow up. Mean (SD) VAS was 7.12 ( 0.86) before operation and reduced to 1.46 ( 1.31 ) after operation at $3 \mathrm{rd}$ (12 months) follow up. Maximum 20 (80\%) patients were satisfied with the treatment.

\begin{tabular}{|c|c|c|}
\hline Level & Frequency & Percentage \\
\hline Single & 9 & 36 \\
\hline L4-L5 & 5 & 20 \\
\hline L5-S1 & 4 & 16 \\
\hline Multiple & 16 & 64 \\
\hline L2-L3 + L3-L4 & 2 & 8 \\
\hline L2-L3 + L3-L4 + L4-L5 & 4 & 16 \\
\hline L3-L4 + L4-L5 + L5-S1 & 3 & 12 \\
\hline L4-L5 + L5-S1 & 7 & 28 \\
\hline
\end{tabular}
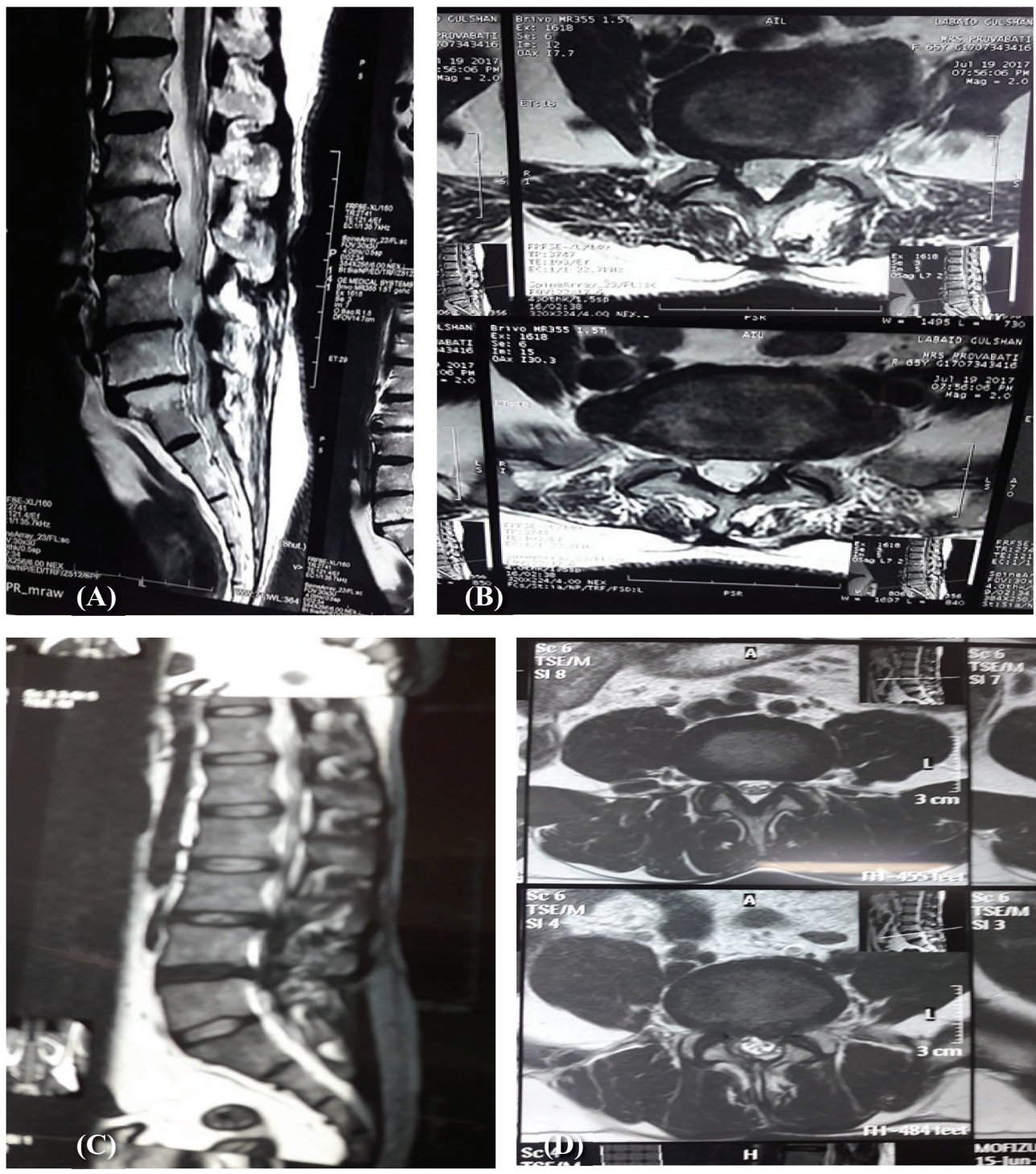

Figure 1 A,C- Preoperative sagital MRI and B,D- Preoperative axia MRI

Showing degenerative lumbar spinal canal stenosis at L3-L4, L4-L5 and L5-S1 level. 
Table II Type of stenosis:

\begin{tabular}{lcc}
\hline Type & Frequency & Percentage \\
\hline Central & 13 & 52 \\
Lateral & 4 & 16 \\
Foraminal & 8 & 32 \\
\hline
\end{tabular}

Table III Decompressive operations:

\begin{tabular}{lcc}
\hline Name of operation & Frequency & Percentage \\
\hline Laminotomy and Discectomy & 12 & 48 \\
Laminectomy and Discectomy & 6 & 24 \\
Laminotomy, Discectomy \& & 4 & 16 \\
Foraminotomy & & \\
Laminotomy\&Foraminotomy & 2 & 08 \\
Laminectomy, Discectomy, & 1 & 04 \\
Foraminotomy and Stabilization & & \\
\hline
\end{tabular}

Table IV Distribution of patients by Modified MacnabCritenic $(\mathrm{N}=25)$

\begin{tabular}{lcccc}
\hline & Poor & Fair Good & Excellent \\
\hline Before operation & 21 & 4 & & \\
At the time of discharge & 2 & 18 & 5 & \\
1st follow up (3 month) & 5 & 13 & 7 & \\
2nd follow up (6 month) & 3 & 9 & 9 & 4 \\
3rd follow up (12 month) & 1 & 4 & 12 & 8 \\
\hline
\end{tabular}

Table $\mathbf{V}$ Result of patients by ODI and VAS:

\begin{tabular}{|c|c|c|}
\hline & Mean \pm SD & Min - Max \\
\hline \multicolumn{3}{|c|}{ Oswestry Disability Index (ODI): } \\
\hline Before operation & $75.40 \pm 5.01$ & $60.0-80.0$ \\
\hline At 12 month follow up & $18.36 \pm 13.54$ & $5.0-60.0$ \\
\hline \multicolumn{3}{|c|}{ Visual Analogue Scale (VAS): } \\
\hline Before operation & $7.12 \pm 0.86$ & $6.0-9.0$ \\
\hline At 12 month follow up & $1.46 \pm 1.31$ & $0.0-5.0$ \\
\hline
\end{tabular}

Table VI Final outcome

\begin{tabular}{lcc}
\hline Type & Frequency $(\mathrm{N}=25)$ & Percentage \\
\hline Satisfactory & 20 & 80 \\
Unsatisfactory & 5 & 20 \\
\hline
\end{tabular}

\section{Discussion}

Degenerative LSCS usually occurs in middle age and old patients. Diagnosis delay is a common problem. It is necessary to obtain a detailed patient's history, clinical and radiological investigations for proper diagnosis. MRI findings have led us to detect the lesion localization, involvement of disc, hypertrophied ligamentumflavum and facet joint and its compressive effect on spinal cord and nerve root.

The satisfactory result of the surgery of LSCS patients largely depends on appropriate patient selection and surgery is required with increasing frequency in management of degenerative LSCS.

In our study maximum $56 \%$ patients were in age group 41-50 years. Mean (SD) age was $48.50( \pm 8.65)$ within the range of 38-65 years and males 19 (76\%) were predominant by females $6(24 \%)$. But in the study of Nath et al. ${ }^{6}$ (2012), pao et al. ${ }^{7}$ (2009) andjoles et al. ${ }^{8}$ (2011), the mean age was 45.1 years, 62.0 years and 61.0 years respectively and male $(73.3 \%)$ were also predominant than females $(26.7 \%)$.

In this study maximum $16(64 \%)$ patients were manual worker and the rest $9(36 \%)$ patients were sedentary worker. Maximum $16(64 \%)$ patients had multilevel stenosis, $9(36 \%)$ patients had single level stenosis and most common level of involvement was L4/L5 level 19 (76\%) patients which was almost similar to other studies. ${ }^{6,7}$

According to MRI findings, in our study 13(52\%) patients had central stenosis, $4(16 \%)$ patients had lateral stenosis and $8(32 \%)$ patients had foraminal stenosis which was consistent with the study of Sirvanciet al. ${ }^{9}$. In this study $22(88 \%)$ patients had low back pain, 21 (84\%) patients had low back pain and leg pain, $20(80 \%)$ patients had neurogenic claudication, $13(52 \%)$ patients had weakness in lower limbs and $1(04 \%)$ patient had bowel and bladder involvement which were almost similar to the study of Cavusogluet al. ${ }^{10}$

In connection to the type of decompressive operations, maximum $12(48 \%)$ patients had laminotomy and discectomy followed by $6(24 \%)$ patients had laminectomy and discectomy, $4(16 \%)$ patients had laminotomy, discectomy and foraminotomy, 2 (08\%) patients had laminotomyandforaminotomy and $1(04 \%)$ patient had laminectomy, discectomy, foraminotomy and stabilization. But in the study by Nathet $\mathrm{al}^{6}{ }^{6}$ (2012), they 
performedlaminectomy $(6.30 \%)$, laminotomy and discectomy (71.8\%), Laminotomy and discectomywith instrumented stabilization (15.6\%) and laminotomy and discectomy with posterior interbody fusion (6.3\%).

Regarding operative complications, 1 (04\%) patient had discitis. Discitis was treated with bed rest, sensitive antibiotic and analgesic. 1 (04\%) patient had superficial wound infection that was treated with regular dressing and sensitive antibiotic. 1 (04\%) patient had dural tear that was repaired with 5/0 vicryl.

According to MMC, most of the patients 21 (84\%) was poor before operation. But after operation at 12 months follow up, 8 (32\%) patients had excellent, 12 (48\%) patients had good, 4 (16\%) had fair \& 1 (04\%) patient had poor functional outcome. In the study of Nathet al.6 (2012), 64\% patients had excellent, $28 \%$ had good and $8 \%$ patients had fair outcome after 12 month follow up.

Mean (SD) ODI was 75.40 ( 5.01) before operation which was significantly improved to a mean 18.36 ( 13.54) $(\mathrm{P}<0.002)$ after operation at 12 month follow up which was all most similar to other studies. ${ }^{7,9}$.

Mean (SD) VAS was $7.12(0.86)$ before operation and reduced to $1.46(1.31)(\mathrm{P}<0.003)$ after operation at 12 months follow up which was similar to other study. ${ }^{10}$

Regarding the subjective assessment of this series, it was observed that $8(32 \%)$ patients had excellent, 12 (48\%) patients had good, $4(16 \%)$ patients had fair and $1(04 \%)$ patient had poor functional outcome. In this study, overall a satisfactory result was found in $20(80 \%)$ cases and unsatisfactory in $5(20 \%)$ cases.

\section{Conclusion}

LSCS is a complex clinical syndrome resulting from degenerative changes in lumbar spines. Based on the result shown above, it is concluded that decompressive operative procedure in the treatment of degenerative
LSCSis an effective, safe and acceptable method. It reduces overall disability and increases the chance of successful outcome.

Conflict of interest: Nothing to declare.

\section{References}

1. Hart LG,Deyo RA, Cherkin DC. Physician office visits for low back pain. Frequency, clinical evaluation, and treatment patterns from a U.S. national survey. Spine 1995; 20(1): 11-19.

2. Sairyo K, Biyani A, Goel V, Leaman D. The mechanism of ligamentumflavum hypertrophy: a multidisciplinary investingation based on clinical, biomechanical, histologic, and biologic assessments. Spine, 2005; 30(23):2649-56.

3. Herno A, Airaksinen O, Saari T, Luukkonen M. Lumbar spinal stenosis: a matched-pair study of operated and non-operated patients; British J Neurosurg 1996; 10: 461-65.

4. SenguptaDk, Herkowitz HN, Lumbar canal stenosis Management strategies and indication of surgery. OrthopClin North Am.2003; 34:281-95.

5. Wiltse LL, Kiraldy-Willis WH, Malvor GW. Management of spinal stenosis. ClinOrthopRelat Res. 1976; 115:83-91.

6. Nath R, Middha S, Gupta AK, Nath R, Functional outcome of surgical management of degenerative lumbar canal stenosis. Indian J Orthop 2012; 46(3): 285-90.

7. Pao JL, chen WC, Chen PQ. Clinical outcomes of micro endoscopic decompressivelaminotomy for degenerative lumbar spinal stenosis. Eur Spine J 2009 18:672-78.

8. Jolles BM, Porchet F and Theumann N. Surgical management of lumbar spinal stenosis. Five-year follow up. J Bone joint Surg.Br 2001;83:949-53.

9. Sirvanci M, Bhatia M, Ganiyusufoglu KA, Duran C, Tezer M, Ozturk C et al. Degenerative lumbar canal stenosis: correlation with Oswestry Disability Index and MR Imaging. Eur Spine J 2008; 17:679-85.

10. Cavusoglu H. Kaya RA, Turkmenoglu ON, Tuncer C, Colak 1, Aydin Y. Midterm outcome after unilateral approach for bilateral decompression of lumbar spinal stenosis : 5 year prospective study. Eur Spine J 2007;16:2133-42

11. Macnab 1. Negative disc exploration and analysis of the cause of nerve root involvement in sixty-eight patients. J Bone Joint Surg (Am) 1971;53:891-03. 